Öffentlichkeit - Geschichte eines kritischen Begriffs 


\section{Öffentlichkeit - Geschichte eines kritischen Begriffs}

Unter Mitarbeit von Russell A. Berman, Karen Kenkel und Arthur Strum

herausgegeben von Peter Uwe Hohendahl

Verlag J. B. Metzler

Stuttgart . Weimar 
Die Deutsche Bibliothek - CIP-Einheitsaufnahme

Öffentlichkeit - Geschichte eines kritischen Begriffs / unter Mitarb. von Russell A. Berman ...

hrsg. von Peter Uwe Hohenhdahl. - Stuttgart ; Weimar : Metzler, 2000

ISBN 978-3-476-01661-4

ISBN 978-3-476-01661-4

ISBN 978-3-476-01721-5 (eBook)

DOI 10.1007/978-3-476-01721-5

Dieses Werk einschließlich aller seiner Teile ist urheberrechtlich geschützt. Jede Verwertung außerhalb der engen Grenzen des Urheberrechtsgesetzes ist ohne Zustimmung des Verlages unzulässig und strafbar. Das gilt insbesondere für Vervielfältigungen, Übersetzungen, Mikroverfilmungen und die Einspeicherung und Verarbeitung in elektronischen Systemen.

(C) 2000 Springer-Verlag GmbH Deutschland

Ursprünglich erschienen bei J. B. Metzlersche Verlagsbuchhandlung

und Carl Ernst Poeschel Verlag GmbH in Stuttgart 2000 
Die einzelnen Kapitel bzw. Abschnitte wurden verfaßt von:

I.-III.2.: Peter Uwe Hohendahl

III.3.-III.6.: Karen Kenkel

(übersetzt aus dem Englischen von Rahel Hahn)

IV.: $\quad$ Russell Berman

V.: $\quad$ Arthur Strum

(übersetzt aus dem Englischen von Tino Markworth)

Die Einleitung zur Bibliographie wurde übersetzt von Awino Kürth.

Die redaktionelle Betreuung übernahm Christiane Hitzemann. 


\section{Inhaltsverzeichnis}

I. Einleitung ...............................................................................

1. Probleme des Begriffsfeldes ..................................................... 1

2. Vorbemerkungen zur Wortgeschichte ...................................... 5

II. Die Entstehung der modernen Öffentlichkeit im Zusammenhang mit der Entstehung des modernen Publikums .............................. 8

1. Zur Geschichte des Wortgebrauchs ......................................... 8

2. Entstehung und Geschichte des Publikums ........................... 12

3. Kritischer Diskurs und öffentliche Meinung ......................... 17

4. Die öffentliche Dimension der ästhetischen Debatte ............. 25

5. Die Radikalisierung der Öffentlichkeit ................................... 31

III. Die klassische Öffentlichkeit im Liberalismus $1815-1880$.......... 38

1. Politische Öffentlichkeit: ihre Theorie und ihre Verwirklichung .................................................................... 38

2. Die Organisation des Publikums im kulturellen Bereich........ 50

3. Marx' Kritik der bürgerlichen Öffentlichkeit; ....................... 54 vormärzliche Radikalisierung der liberalen Öffentlichkeit; Problematisierung des Publikums im ästhetischen Diskurs .... 54

4. Nachmärz ....................................................................... 62

5. Majorité und Masse als bedrohliche Phänomene ................... 66

6. Industrielle Kultur und die Kritik der kritischen Öffentlichkeit

IV. Moderne, Modernismus und Öffentlichkeit 1880-1960 ............ 75

1. Zerfall der klassischen Öffentlichkeit ...................................... 75

2. Ästhetische Moderne und Öffentlichkeit ................................ 77

3. Strukturwandel der Literaturkritik ......................................... 79

4. PPublic Opinion

5. Akklamatorische Öffentlichkeit ............................................. 85

6. Kritische Öffentlichkeit und Kulturindustrie ......................... 88 
V. Öffentlichkeit von der Moderne zur Postmoderne: 1960-1999 .. 92

1. Demokratie und Öffentlichkeit in der Nachkriegszeit ........... 92

2. Normativität und totalitarisierende Öffentlichkeit:

Koselleck und Luhmann ...................................................... 99

3. Gegen-Öffentlichkeiten und die Kritik des liberalen Modells

4. Öffentlichkeit nach der Wende: Zivilgesellschaft und Gegenöffentlichkeiten in der Mediengesellschaft .....

Eine Bibliographie zum Begriff der Öffentlichkeit 